\title{
The Direct/Indirect Association of ADHD/ODD Symptoms with Self- esteem, Self-perception, and Depression in Early Adolescents
}

\author{
Yosuke Kita ${ }^{\text {*t }}$ and Yuki Inoue $\mathrm{e}^{1,2,3+}$ \\ 'Department of Developmental Disorders, National Institute of Mental Health, National Center of Neurology and Psychiatry \\ (NCNP), Tokyo, Japan, ${ }^{2}$ Department of Child Psychiatry, Shimada Ryoiku Center Hachioji, Tokyo, Japan, ${ }^{3}$ Department of \\ Child Psychiatry, Yokohama City Southern Area Habilitation Center for Children, Yokohama, Japan
}

\section{OPEN ACCESS}

Edited by:

Hanna E. Stevens,

University of lowa,

United States

Reviewed by:

Yoshifumi lkeda,

Joetsu University of

Education, Japan

Rajshekhar Bipeta,

Gandhi Medical College and

Hospital, Hyderabad, India

${ }^{*}$ Correspondence:

Yosuke Kita

kitay@ncnp.go.jp

tThese authors have contributed equally to this work.

Specialty section: This article was submitted to Child and Adolescent Psychiatry, a section of the journal

Frontiers in Psychiatry

Received: 23 March 2017 Accepted: 13 July 2017

Published: 31 July 2017

Citation:

Kita Y and Inoue Y (2017) The Direct/ Indirect Association of ADHD/ODD

Symptoms with Self-esteem,

Self-perception, and Depression

in Early Adolescents.

Front. Psychiatry 8:137.

doi: 10.3389/fpsyt.2017.00137
The present study aimed to reveal the influences of attention-deficit hyperactivity disorder (ADHD) and oppositional defiant disorder (ODD) symptoms on self-esteem and self-perception during early adolescence and to clarify the spillover effect of self-esteem on depressive symptoms. ADHD symptoms in 564 early adolescents were evaluated via teacher-rating scales. Self-esteem and depressive symptoms were assessed via selfreported scales. We analyzed the relationships among these symptoms using structural equation modeling. Severe inattentive symptoms decreased self-esteem and hyperactive-impulsive symptoms affected self-perception for non-academic domains. Although these ADHD symptoms did not directly affect depressive symptoms, low self-esteem led to severe depression. ODD symptoms had a direct impact on depression without the mediating effects of self-esteem. These results indicated that inattentive symptoms had a negative impact on self-esteem and an indirect negative effect on depressive symptoms in adolescents, even if ADHD symptoms were subthreshold. Severe ODD symptoms can be directly associated with depressive symptoms during early adolescence.

Keywords: attention-deficit hyperactivity disorder, oppositional defiant disorder, depression, self-esteem, structural equation modeling

\section{INTRODUCTION}

Attention-deficit hyperactivity disorder (ADHD) is a neurodevelopmental condition with an estimated prevalence of $5 \%$ in children worldwide (1). ADHD is characterized by a developmentally inappropriate level of inattention and hyperactivity/impulsivity. It persists from childhood to adulthood, interfering with functioning in several domains (2). Academic and educational outcomes are significantly lower in children with ADHD. For example, ADHD is associated with poor grades, increased rates of detention and expulsion, and low rates of high school graduation (3). Children with ADHD are also likely to experience a greater number of negative social events, such as being rejected by peers, having poor social skills (4), and having frequent negative interactions with their mothers (5).

These negative experiences can have a large impact on self-esteem in children with ADHD. According to the multidimensional model of self-esteem (6), children who frequently experience failure are at risk of developing a lower sense of self-competence. Conversely, children who often experience success may develop an enhanced sense of self-efficacy. Over the past three decades, a number of studies focused on self-esteem in children with ADHD [for review, see Ref. $(7,8)$ ] have led to the recognition of self-esteem as an important topic affecting individuals with ADHD. 
According to one such review (8), more than half of previous studies found that children with ADHD had lower self-esteem compared with healthy controls. However, some children with ADHD rate their quality of life as being less negative compared with evaluations made by their parents (7). Children with ADHD also tend to overestimate their own competence [for review, see Ref. $(9,10)]$. Thus, it is unclear whether children with ADHD symptoms have low self-esteem during childhood owing to negative life experiences.

Previous studies have consistently reported low self-esteem in adults with ADHD [for review, see Ref. (11)]. Additionally, studies exploring gender differences in self-esteem found a decrease in this population regardless of gender (12-14). Two studies $(15,16)$ exploring gender differences pointed out that self-esteem in adults with ADHD is lower for those with combined type vs. inattentive type (15). Based on these findings regarding childhood and adulthood, we speculated that people with ADHD symptoms follow a developmental course in which their self-esteem gradually decreases until adulthood, even if they have high self-esteem during childhood.

Relatively, few studies have focused on adolescent ADHD. While previous studies have discussed the relationships between ADHD symptoms and self-esteem in both children and adults, the relationship between these two developmental stages is unclear. One study found a significant relationship between parent-rated and self-reported ADHD symptoms in adolescents aged 13 (17). Scholtens et al. (18) conducted a community sample study and reported that ADHD symptoms had a negative effect on academic progress and academic self-perception. Additionally, Glass et al. (19) examined the relationship between self-esteem and conduct problems in adolescents with ADHD and reported that self-esteem was significantly lower in adolescents with ADHD and conduct problems but not in adolescents with ADHD only. Based on these findings, we hypothesized that self-esteem in people with ADHD symptoms decreases with age from childhood to adulthood and that adolescence is a transitional stage in which ADHD symptoms affect both self-esteem and internal problems such as depressive symptoms. This is likely related to the gradual increase in the total amount of negative experiences related to ADHD symptoms along the lifespan of an individual. We sought to fill in the gaps between childhood and adulthood, focusing on the relationship among ADHD symptoms, self-esteem, and internal behavioral problems.

The first aim of the current study was to examine the influence of ADHD symptoms on self-esteem in early adolescence, with a focus on school-based samples. Because clinical adolescent participants with ADHD often have very complicated mental and/ or behavioral problems, evaluations of ADHD symptoms might be distorted by comorbid disorders in such samples. Moreover, recent studies suggested that ADHD symptoms are considered as a continuum rather than a dichotomous condition $(20,21)$, which encouraged us to focus on typically developing adolescents who have subthreshold ADHD symptoms. Thus, we performed a school-based study to investigate the relationships between ADHD symptoms and self-esteem in adolescents.

The second aim of the current study was to clarify the relationships between self-esteem and other clinical symptoms, such as behavioral and depressive symptoms, which are frequently comorbid with ADHD in adolescents. While ADHD symptoms are thought to affect self-esteem, behavioral problems such as oppositional defiant disorder (ODD) are also known to be contributing factors. Previous studies have indicated that co-occurring aggressive behavior is related to enhanced selfestimations [for review, see Ref. (9)]. Moreover, self-esteem usually impacts depressive symptoms, such that lower self-esteem can easily lead to severe depressive symptoms in children (22). This tendency appears to be more pronounced in adolescents compared with children, which is expected based on the typical developmental trajectory (23).

Given the aims stated previously, we investigated the relationships among ADHD symptoms, ODD symptoms, selfesteem, and depressive symptoms in adolescents based on our hypothetical model (Figure 1). As illustrated in Figure 1, we expected that ADHD and ODD symptoms affect self-esteem and self-perception, which have been shown in previous studies about children and adults with $\operatorname{ADHD}(7,11)$. Self-esteem and self-perception would have influences on depressive symptoms in adolescents $(20,21)$. Moreover, the depressive symptoms might be affected by ADHD and ODD symptoms because the high rates of the comorbidity of $\mathrm{ADHD} / \mathrm{ODD}$ and depression have been also reported in clinical samples $(24,25)$. We had these hypothetical associations and conducted our analysis via structural equation modeling (SEM).

\section{MATERIALS AND METHODS}

\section{Participants and Procedure}

Participants comprised 564 children, ranging in age from 12 to 15 years, from two local public middle schools. Prior to engagement in the study, we provided sufficient explanations about the details of the study to the school principals, children, and their parents. We obtained school approval and written informed

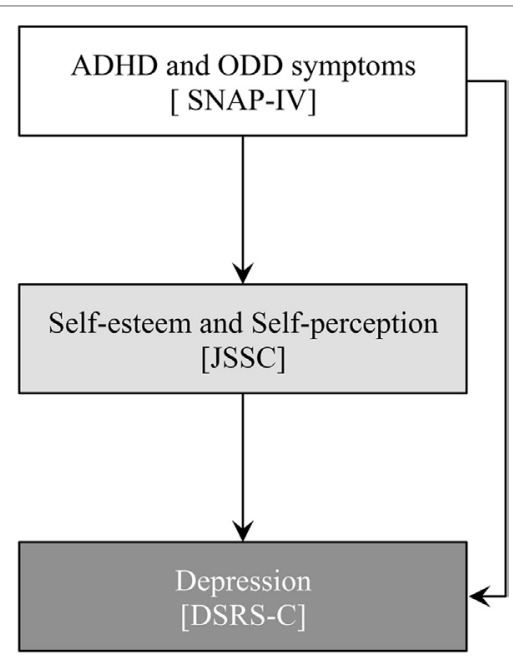

FIGURE 1 | Hypothetical model of relationships between attention-deficit hyperactivity disorder (ADHD) and oppositional defiant disorder (ODD) symptoms, self-esteem, self-perception, and depression. 
consent from all schools and parents, respectively, prior to study participation. To limit our participant sample to typically developing children without severe neurological or psychiatric disorders, we did not include children engaged in special education. Some children made mistakes in their responses, resulting in a valid response rate of $66.4 \%$. The rate seemed to be relatively low because we adopted listwise deletions of cases for the statistical analyses (i.e., we excluded children who have at least one missing value in all questionnaires). Thus, the final sample comprised 374 children (194 boys and 180 girls). The average age of the participants was 13.69 years $(\mathrm{SD}=0.89)$ (Table 1$)$, and all participants were native-born Japanese children. The research protocol was approved by the ethics committee at the Shimada Ryoiku Center Hachioji (Tokyo, Japan; approval number 201503).

\section{Measures}

\section{ADHD and ODD Symptoms}

We used a Japanese version of the Swanson, Nolan, and Pelham Rating Scale-IV (SNAP-IV) Teacher form (26) to assess symptoms of ADHD and ODD. The original version of the SNAP-IV was used as a primary outcome measure in the Multimodal Treatment of Attention Deficit Hyperactivity Disorder study $(27,28)$, and has been translated into languages other than English with high reliability and validity $(26,29)$. The SNAP-IV is a 26 -item questionnaire that comprises three factors: Inattention ( 9 items), Hyperactivity-Impulsivity (9 items), and ODD (8 items). Each item is measured on a four-point Likert scale ranging from 0 ("not at all") to 3 ("very much"), and each factor score is calculated by taking the mean of the items. Higher scores on the factors reflect more severe symptoms, and we set the cutoff values for Inattention and Hyperactivity-Impulsivity as 2.56 and 1.78, respectively. Classroom teachers, who spent over $20 \mathrm{~h}$ /week with the children, evaluated the participant symptoms. The SNAP-IV was administrated to them in their school as a paper-and-pencil questioner.

\section{Self-esteem and Self-perception}

We measured self-esteem and self-perception via the Japanese version of the Scale of Self-Cognition [JSSC (30)]. The JSSC is a 26-item self-reported questionnaire for children ranging in age from 8 to 15 years, and was translated from the original "SelfPerception Profile for Children" scale $(6,31)$. The JSSC has two main factors: Global Self-Worth (i.e., self-esteem) and domainspecific judgments (i.e., self-perception). The former factor is assessed via six items, and the latter factor is divided into five

TABLE 1 | Number of participants (upper lines) and mean ages with standard deviations ( $\mathrm{M} \pm \mathrm{SD}$; lower lines).

\begin{tabular}{lccc}
\hline & Boy & Girl & Sum \\
\hline First grade (12-13 years) & 65 & 70 & 135 \\
& $12.75 \pm 0.29$ & $12.67 \pm 0.28$ & $12.71 \pm 0.29$ \\
Second grade (13-14 years) & 54 & 52 & 106 \\
& $13.67 \pm 0.27$ & $13.68 \pm 0.3$ & $13.67 \pm 0.29$ \\
Third grade (14-15 years) & 75 & 58 & 133 \\
Sum & $14.66 \pm 0.27$ & $14.73 \pm 0.27$ & $14.69 \pm 0.27$ \\
& 194 & 180 & 374 \\
& $13.75 \pm 0.86$ & $13.62 \pm 0.91$ & $13.69 \pm 0.89$
\end{tabular}

specific domains: Scholastic Competence (five items), Athletic Competence (four items), Behavioral Conduct (three items), Social Acceptance (three items), and Physical Appearance (five items). Children were asked to respond to each item using a fourpoint Likert scale ranging from 1 ("not at all") to 4 ("very much") when they were in school (i.e., a paper-and-pencil questioner). Scores for each of six subscales (i.e., one for self-esteem and five for self-perception) were calculated by taking the mean of the items. Higher scores on the subscales reflected higher levels of self-esteem or self-perception.

\section{Depression}

We assessed depression in children via the Japanese version of the Depression Self-Rating Scale for Children (DSRS-C (32)). The DSRS-C has high validity and reliability $(33,34)$ and is suitable for children because it consists of just 18 easy items. Children use a three-point Likert scale ranging from 0 ("not at all") to 2 ("most of the time") to respond to each item when they were in school (i.e., a paper-and-pencil questioner). Depression score is calculated by summing the item scores. Higher scores indicate more severe depressive symptoms, and we set a cutoff score of 16 for identifying depressed children (32).

\section{Data Analysis}

We generated descriptive statistics for each measurement. We also calculated the percentages of children with scores above the cutoff values for Inattention and Hyperactivity-Impulsivity in the SNAP-IV, and Depression in the DSRS-C. We calculated Pearson's correlation coefficients to examine the relationships among all valuables. We examined gender differences for three factors in the SNAP-IV, Depression scores, and Global Self-Worth using one-way $t$-tests. We tested self-perception via a two-way repeated measures ANOVA [gender (2) $\times$ domains (5)] followed by post hoc analysis with the Bonferroni adjustment. We used SEM to study our hypothesis regarding the relationship between ADHD and ODD symptoms, depression, self-perception, and self-esteem. We examined the suitability of our hypothetical model using maximum likelihood estimation techniques. We used multiple fit indices, such as the ratio between the chi square statistic and the Degrees of Freedom $\left(\chi^{2} / d f\right)$, the Goodness-of-Fit Index (GFI), the Adjusted Goodness-of-Fit Index (AGFI), the Comparative Fit Index (CFI), and the Root Mean Square Error of Approximation (RMSEA) to evaluate model fit. We set the statistical criteria for a good fit between the model and data as follows: $\chi^{2} / d f<5$ (35), GFI $>0.95$, AGFI $>0.95$, CFI $>0.95$, and RMSEA $<0.05$ $(35,36)$. We examined each path in the model using Wald tests with significance set at $p=0.05$. Statistical analyses were conducted using IBM SPSS Statistics 19 (SPSS Japan Inc., Tokyo, Japan) and IBM SPSS Amos 19 (SPSS Japan Inc., Tokyo, Japan).

\section{RESULTS}

\section{Descriptive Statistics and Correlations}

The average scores for $\mathrm{ADHD}$ and $\mathrm{ODD}$ symptoms were close to 0 , as follows: Inattention $=0.23 \pm 0.42$ (mean \pm SD), Hyperactivity-Impulsivity $=0.06 \pm 0.22$, and $\mathrm{ODD}=0.08 \pm 0.25$. 
The mean score for Depression was also lower than the cutoff value: $9.94 \pm 5.26$. The results for self-esteem and self-perception were as follows: Global Self-Worth $=2.58 \pm 0.65$, Scholastic Competence $=2.42 \pm 0.65$, Athletic Competence $=2.12 \pm 0.80$, BehavioralConduct $=2.50 \pm 0.60$, Social Acceptance $=3.20 \pm 0.66$, and Physical Appearance $=2.29 \pm 0.71$. While all children had scores below the cutoff values for Inattention (i.e., $100.0 \%$ of the total sample), one child had scores above the cutoff value for Hyperactivity-Impulsivity (i.e., $0.3 \%$ of the total sample). 52 children (13.9\% of the total sample; 18 boys and 34 girls) were identified as depressed because they obtained scores above the cutoff value for Depression.

Table 2 presents the correlations among all variables. ADHD and ODD symptoms were positively correlated with one another $(r s>0.59, p s<0.001)$. These symptoms were also negatively associated with self-perception in terms of Scholastic Competence (vs. Inattention $r=-0.26, p<0.001$; vs. Hyperactivity-Impulsivity, $r=-0.18, p<0.001$; vs. ODD, $r=-0.10, p<0.05$ ) and Behavioral Conduct (vs. Inattention $r=-0.25, p<0.001$; vs. Hyperactivity-Impulsivity, $r=-0.26$, $p<0.001$; vs. ODD, $r=-0.22, p<0.001)$. While ODD symptoms were positively associated with Depression $(r=0.21, p<0.001)$, this was not the case for both Inattention and HyperactivityImpulsivity ( $p$ s $>0.05$ ). We found significant positive correlations between all associations with respect to the six factors in the JSSC ( $r s>0.14, p s<0.01)$ except that between Behavioral Conduct and Social Acceptance $(r s=0.01, p>0.05)$. Depression was negatively associated with all factors in terms of self-esteem and self-perception $(r s<-0.25, p s<0.001)$.

\section{Gender Differences}

Compared with girls, boys obtained higher scores for Inattention $[t(372)=3.73, p<0.001]$ and Hyperactivity-Impulsivity $[t(372)=2.26, p=0.024]$. Gender differences were not significant for ODD score $[t(372)=0.87, p=0.383]$ (Figure 2A). However, girls obtained a higher Depression score $[t(372)=2.670$, $p=0.008$ ] (Figure 2B) and a lower score for Global Self-Worth $[t(372)=4.11, p<0.001]$. Figure 3 shows comparisons of selfperception scores between the genders. A two-way repeated measures ANOVA revealed a significant interaction between gender and domain $[F(4,1,488)=12.111, p<0.001]$. Post hoc analyses indicated that boys scored higher than girls with respect to Scholastic Competence, Athletic Competence, and Physical Appearance ( $p s<0.001)$. For boys, the highest score was for Social Acceptance and the lowest score was for Athletic Competence. Girls received scores in the following order, ranked from highest to lowest: Social Acceptance, Behavioral Conduct, Scholastic Competence, Physical Appearance, and Athletic Competence $(p s<05)$.

\section{Relationships among ADHD and ODD Symptoms, Depression, Self-perception, and Self-esteem}

As a first test step, we used the SEM to evaluate our hypothetical model (Figure 1), which set all paths between the observed variables. This first test step produced several inadequate values of fit indices, such as $\chi^{2} / d f=41.72$ and GFI $=0.62$. Thus, we modified the first model by removing paths that were insignificant. Moreover, we added the residual error covariance between factors associated with ADHD and ODD symptoms, and domains in self-perception, based on modification indices. We repeated these modification procedures to reach the final modified model, shown in Figure 4. The SEM produced fit indices that indicated a good fit between the final model and data $\left[\chi^{2}(18)=31.37\right.$, $p=0.03 ; \chi^{2} / d f=1.743 ; \mathrm{GFI}=0.984 ; \mathrm{AGFI}=0.952$; $\mathrm{CFI}=0.989$; RMSEA $=0.048]$.

All paths in the final model were significant according to the Wald test ( $p s<0.05$ ) (Figure 4). Inattention was associated with self-esteem and self-perception. Specifically, severe inattentive

TABLE 2 | Correlation coefficients among the variables.

\begin{tabular}{|c|c|c|c|c|c|c|c|c|c|c|c|}
\hline & Age & Inattention & $\begin{array}{l}\text { Hyperactivity- } \\
\text { Impulsivity }\end{array}$ & ODD & $\begin{array}{l}\text { Scholastic } \\
\text { Competence }\end{array}$ & $\begin{array}{c}\text { Athletic } \\
\text { Competence }\end{array}$ & $\begin{array}{l}\text { Behavioral } \\
\text { Conduct }\end{array}$ & $\begin{array}{c}\text { Social } \\
\text { Acceptance }\end{array}$ & $\begin{array}{c}\text { Physical } \\
\text { Appearance }\end{array}$ & $\begin{array}{c}\text { Global } \\
\text { Self- } \\
\text { worth }\end{array}$ & Depression \\
\hline Age & - & -0.03 & -0.08 & $-0.11^{\star}$ & 0.03 & 0.06 & $0.26^{\star \star \star}$ & -0.06 & -0.08 & -0.05 & 0.03 \\
\hline Inattention & & - & $0.66^{\star \star \star}$ & $0.59^{\star \star \star}$ & $-0.26^{\star \star \star}$ & -0.04 & $-0.25^{\star \star \star}$ & $0.10^{\star}$ & -0.04 & -0.07 & 0.07 \\
\hline $\begin{array}{l}\text { Hyperactivity- } \\
\text { Impulsivity }\end{array}$ & & & - & $0.62^{\star \star \star}$ & $-0.18^{\star \star \star}$ & 0.07 & $-0.26^{\star \star \star}$ & $0.12^{*}$ & 0.02 & 0.04 & 0.05 \\
\hline ODD & & & & - & $-0.10^{\star}$ & 0.04 & $-0.22^{\star \star \star}$ & 0.09 & -0.05 & -0.04 & $0.21^{\star \star \star}$ \\
\hline $\begin{array}{l}\text { Scholastic } \\
\text { Competence }\end{array}$ & & & & & - & $0.33^{\star \star \star}$ & $0.38^{\star \star \star}$ & $0.14^{\star \star}$ & $0.43^{\star \star \star}$ & $0.43^{\star \star \star}$ & $-0.33^{\star \star \star}$ \\
\hline $\begin{array}{l}\text { Athletic } \\
\text { Competence }\end{array}$ & & & & & & - & $0.21^{\star \star \star}$ & $0.47^{\star \star \star}$ & $0.43^{\star \star \star}$ & $0.45^{\star \star \star}$ & $-0.37^{\star \star \star}$ \\
\hline $\begin{array}{l}\text { Behavioral } \\
\text { Conduct }\end{array}$ & & & & & & & - & 0.01 & $0.25^{\star \star \star}$ & $0.35^{\star \star \star}$ & $-0.25^{\star \star \star}$ \\
\hline $\begin{array}{l}\text { Social } \\
\text { Acceptance }\end{array}$ & & & & & & & & - & $0.20^{\star \star \star}$ & $0.28^{\star \star \star}$ & $-0.38^{\star \star \star}$ \\
\hline Physical & & & & & & & & & - & $0.60^{\star \star \star}$ & $-0.40^{\star \star \star}$ \\
\hline Global Self-worth & & & & & & & & & & - & $-0.54^{\star \star \star}$ \\
\hline
\end{tabular}

${ }^{*} p<0.05$.

${ }^{* *} p<0.01$

${ }^{* * *} p<0.001$ 

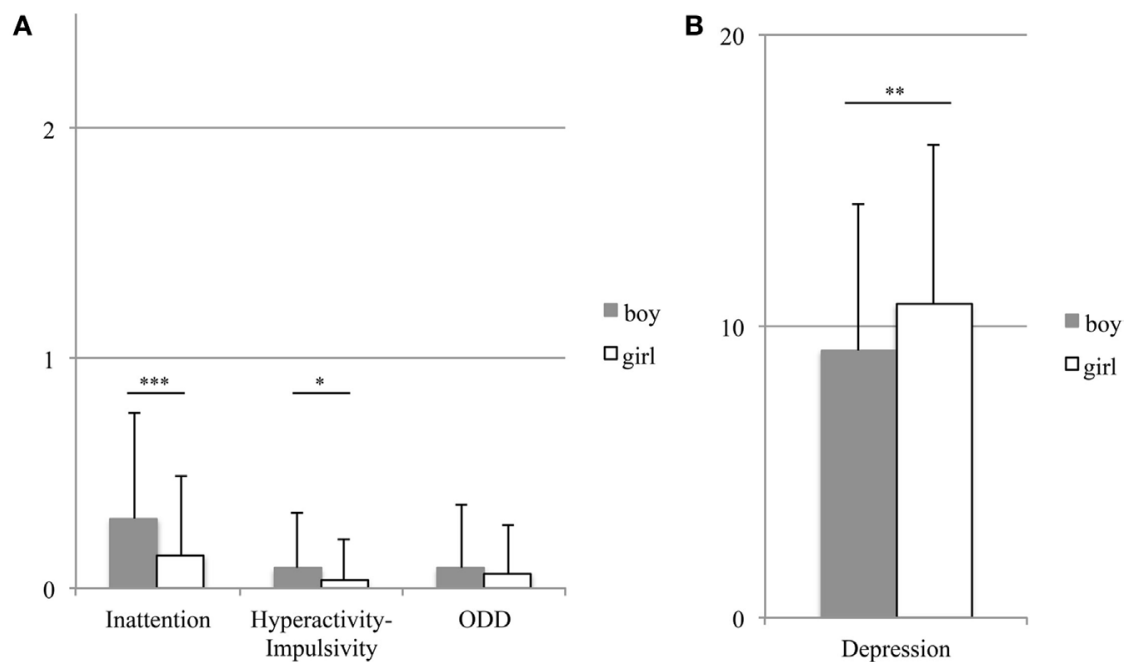

FIGURE 2 | Gender differences in attention-deficit hyperactivity disorder (ADHD) symptoms (A) and depression (B). The bars and error bars show the means and standard deviations, respectively. ${ }^{* * *} p<0.001,{ }^{* \star} p<0.01$, and ${ }^{*} p<0.05$.

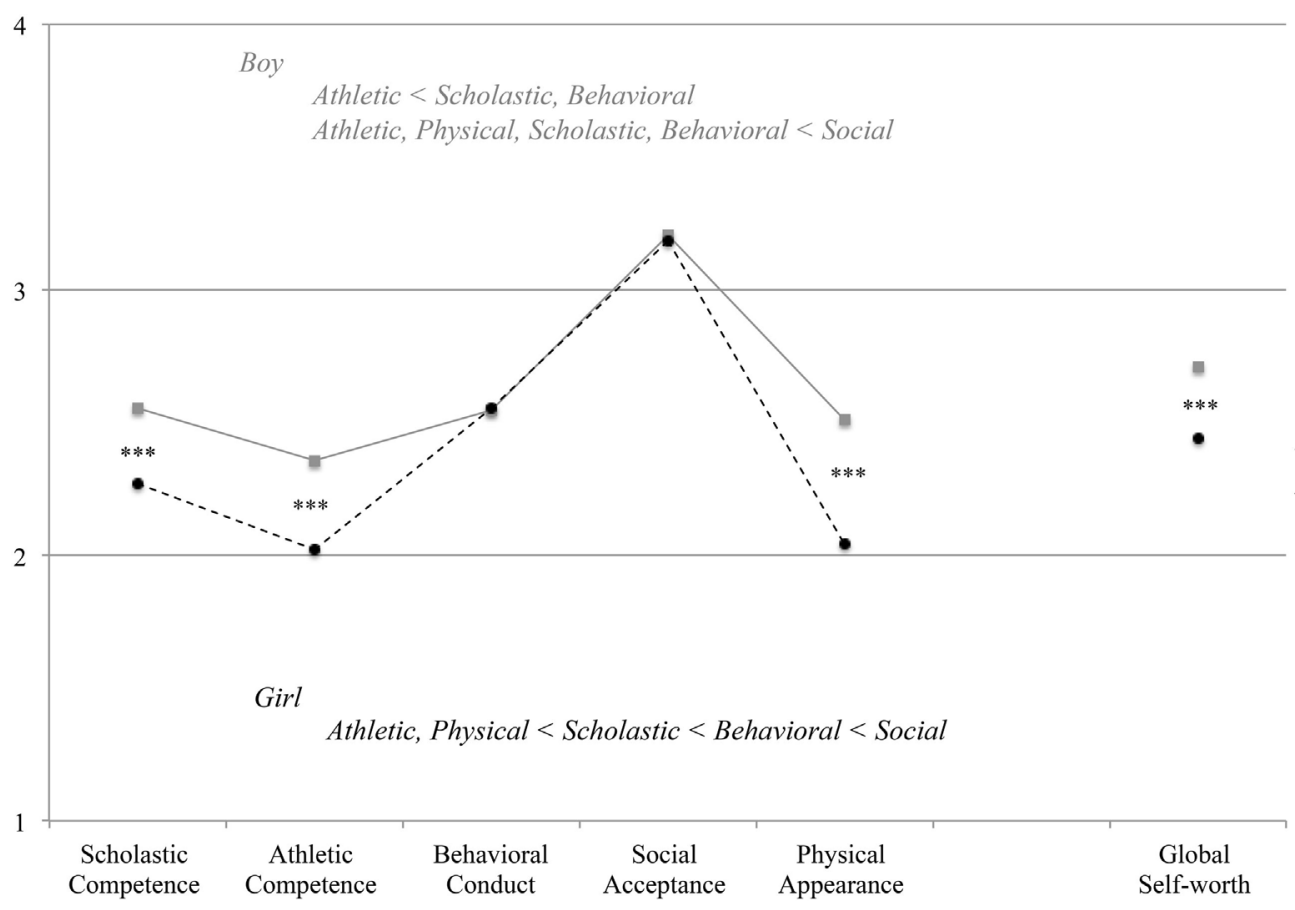

FIGURE 3 | Gender differences in self-esteem and self-perception for five domains. ${ }^{\star \star \star} p<0.001$.

symptoms decreased Global Self-worth (path coefficient $=-0.103$ ), Scholastic Competence (path coefficient $=-0.234$ ), and Athletic Competence (path coefficient $=-0.131$ ). High levels of Hyperactivity-Impulsivity also decreased self-perception with respect to Behavioral Conduct (path coefficient $=-0.250$ ) but increased Athletic Competence (path coefficient $=0.111$ ). We did not find any direct effects of ADHD symptoms on depression, although severe ODD symptoms were associated with severe depression (path coefficient $=-0.212$ ). Greater Global Self-Worth was strongly associated with decreased depression (path coefficient $=-0.390$ ). Moreover, greater self-perception regarding Social Acceptance and Physical Appearance, both of which were not influenced by ADHD symptoms, was associated with decreased depression (path coefficient $=-0.266$ and -0.106 , respectively). However, Scholastic Competence, Athletic Competence, and Behavioral Conduct, which were self-perception 


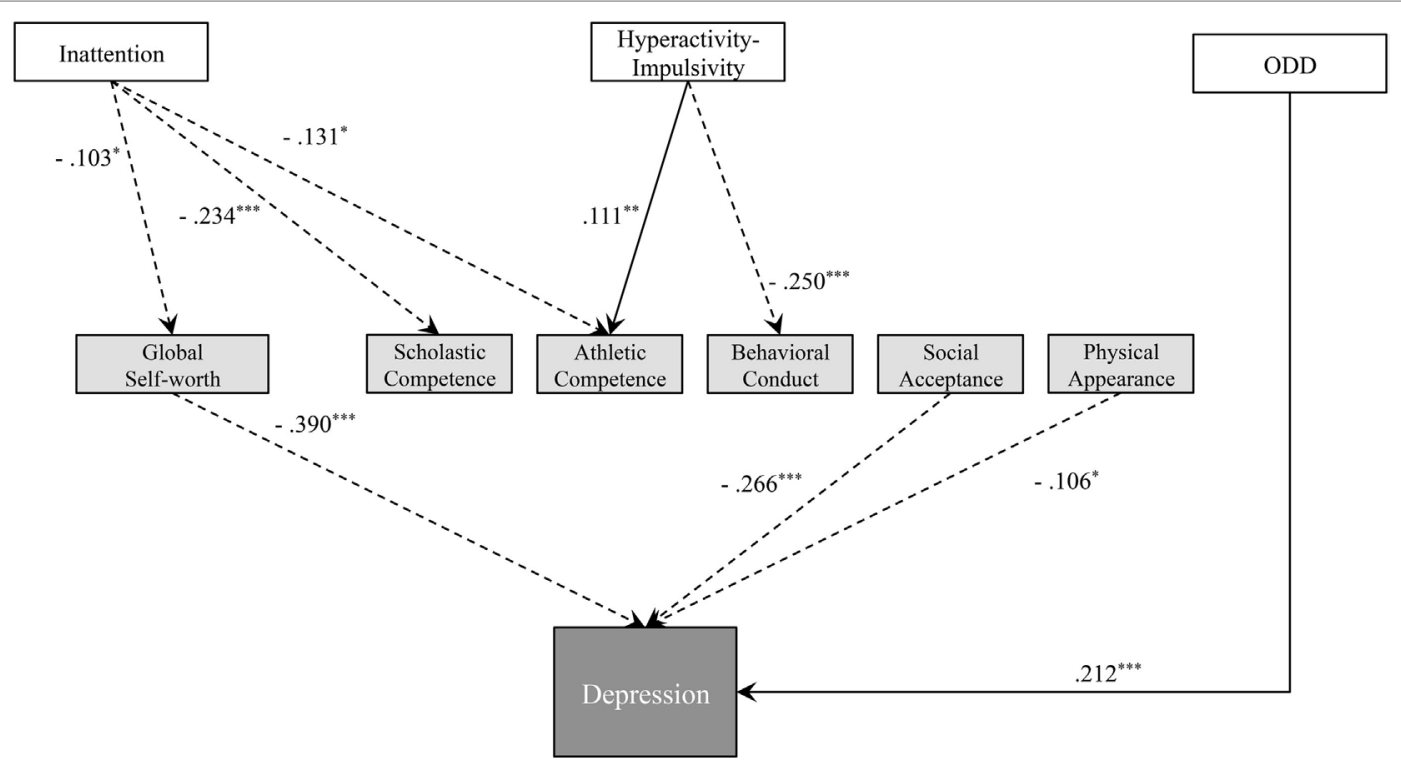

FIGURE 4 | Final model of relationships between attention-deficit hyperactivity disorder (ADHD) and oppositional defiant disorder (ODD) symptoms, self-esteem, self-perception, and depression with standardized path coefficients. The solid and dashed arrows show the positive and negative effects, respectively. ${ }^{\star \star *} p<0.001$, ${ }^{* *} p<0.01$, and ${ }^{*} p<0.05$.

domains influenced by ADHD symptoms, were not significantly associated with depression.

\section{DISCUSSION}

In the present study, we found that inattentive symptoms were associated with decreased Global Self-worth, Scholastic Competence, and Athletic Competence, while hyperactiveimpulsive symptoms were associated with self-perception regarding Behavioral Conduct. Moreover, low self-esteem (i.e., Global Self-worth) and self-perception (Social Acceptance and Physical Appearance) were strongly associated with severe depression. Although ADHD symptoms were not directly associated with depressive symptoms, this was the case for ODD symptoms in early adolescents.

The present data indicate that ADHD symptoms in early adolescents are associated with self-esteem and several domains of self-perception. This is consistent with a previous survey conducted with a community sample (18). The authors found that severe inattentive symptoms were associated with decreased self-perception in terms of scholastic and athletic competence, both of which are related to school activities and classes. Children with severe inattention are more likely to make mistakes on schoolwork and in physical education classes in school, and to be reproached by teachers and parents (37). These reproaches could decrease self-perception in some domains, while individuals may maintain healthy self-perception for other domains, such physical appearance, that are not as likely to draw rebukes from others.

Hyperactive-impulsive symptoms were associated with selfperception in terms of Behavioral Conduct. This domain was evaluated via several questions, such as "I often do something that I know I should not do" and "I think that I cannot behave nicely." Hyperactive-impulsive children often cannot keep themselves from doing things they should not do. They may regret their behaviors later on, particularly when they get scolded by their teachers and other adults for what they have done [e.g., Ref. (38)]. The combination of remorse and reproaches from others may decrease their self-perception regarding behavioral conduct.

Low self-esteem was associated with more severe depressive symptoms. Many previous findings have indicated that children with ADHD have low self-esteem, which can lead to depression $(24,25)$. These internalized problems become pronounced during the transition from childhood to adolescence, and some children with ADHD are first diagnosed with depression during adolescence $(39,40)$. Additionally, it is interesting to note that depression was associated with low self-perception with respect to Social Acceptance and Physical Appearance, which were not influenced by ADHD symptoms. Nishikawa et al. (41) also proposed non-academic self-concept (i.e., social and physical factors) as a predictor of internalizing and externalizing problems in Japanese adolescents. Japanese adolescents assign more importance to friendships and physical appearance compared with school activities such as scholastic and athletic competence. This is likely because Japanese people traditionally emphasize group harmony and compliance with social norms $(42,43)$. Thus, such culturally imbedded attitudes can have a potent influence on the mental health of Japanese adolescents, for instance, making them more susceptible to depressive symptoms if they have low self-perception regarding social and physical appearance.

Oppositional defiant disorder symptoms were directly associated with depressive symptoms, while ADHD symptoms were indirectly associated with depression via self-esteem. Recently, Leadbeater and Homel (44) reported that ODD symptoms among adolescents were linked with both internalizing (anxiety 
and depression) and externalizing (conduct problems) problems. Boylan et al. (45) also indicated that ODD is often comorbid with internalizing disorders (anxiety/depressive disorder) in childhood and adolescence. The present results are consistent with these previous findings and suggest that ODD symptoms might influence depression directly, unlike the relationship between ADHD symptoms and depression mentioned above. Thus, adolescents with ODD symptoms may be at risk for depression, even though their ODD symptoms have a minimal influence on self-esteem and self-perception.

We found gender differences in ADHD symptoms in our sample of Japanese early adolescents. Specifically, boys received higher Inattention and Hyperactive-Impulsivity ratings than girls, while we found no gender differences in ODD symptoms. ADHD symptoms are usually more pronounced in boys compared with girls, regardless of whether measurements are made using parent-rated or teacher-rated scales $(46,47)$. These gender differences tend to decrease with age and are not found among adults in countries other than Japan $(46,48)$. However, the degree of ADHD symptoms in healthy samples can vary from country to country, for example, Japanese university students have higher ratings of inattention than university students in the USA (49). Further studies, based on cultural differences, are needed to confirm whether gender differences in ADHD symptoms decrease from adolescence to adulthood in Japanese samples.

The present study has several limitations. First, ADHD symptoms were evaluated only by teachers and not by parents. Behaviors and mental states of adolescents may vary widely between home to school. Indeed, ADHD symptoms in the present study might have been overestimated or underestimated by teachers, who based their evaluations only on performance at school. Future studies would benefit from examining the gaps between teacher-rated and parent-rated ADHD symptoms and investigate the relationships between parent-rated ADHD symptoms and other factors, such as self-esteem and depression. Second, we did not consider information about the family environment of the adolescents, such as socioeconomic state or parenting attitude. These family factors can have a major impact on mental and physical health in children from infancy to adolescence [e.g., Ref. (50)]. Further studies should include this information to assess the influences both of personal (i.e., ADHD and ODD symptoms) and environmental factors (i.e., family social environment) on self-esteem and depressive symptoms. Third, we did not find any influences of comorbidity of ADHD and ODD on self-esteem, self-perception, and depression. Previous researches indicates high rate of the comorbidity of $\mathrm{ADHD}$ and ODD $(51,52)$, and the present study also found significant correlations between ADHD and ODD symptoms. However, the SEM including the interaction effect of the comorbidity did not produce good-fit indices, meaning that the interaction effect was not confirmed on the present samples. We should examine the influences of comorbidity on self-esteem and depression when we conduct next study on clinical samples. Finally, the present research was a cross-sectional study which does not enable us to confirm causalities among the variables. In the present study, we were aware of the limitations of the cross-sectional study and estimated the associations between the variables based on the statistical analyses. A longitudinal study (i.e., a cohort study) is needed to confirm the causalities that are suggested in the present study.

In conclusion, to the best of our knowledge, this is the first study to examine the relationships among ADHD and ODD symptoms, self-esteem, self-perception, and depressive symptoms in adolescents. Inattentive symptoms were associated with self-esteem and self-perception in terms of scholastic and athletic competence, while hyperactive-impulsive symptoms were associated with self-perception regarding behaviors. However, we did not find a direct effect between ADHD symptoms and depressive symptoms in adolescents. Low self-esteem and self-perception were strongly associated with depression. ODD symptoms, however, were directly associated with depression, without the mediating effects of self-esteem. The present findings indicate that inattentive symptoms have a negative influence on self-esteem and depressive symptoms, even if adolescents have subthreshold ADHD symptoms. Additionally, adolescents with severe ODD symptoms may be at greater risk for depressive symptoms.

\section{ETHICS STATEMENT}

This study was carried out in accordance with the recommendations of "Ethical Guidelines for Medical and Health Research Involving Human Subjects, the ethics committee at the Shimada Ryoiku Center Hachioji (Tokyo, Japan; approval number 201503)"; with written informed consent from all subjects. All subjects gave written informed consent in accordance with the Declaration of Helsinki. The protocol was approved by the "the ethics committee at the Shimada Ryoiku Center Hachioji (Tokyo, Japan; approval number 201503)."

\section{AUTHOR CONTRIBUTIONS}

YK and YI contributed to the design of the study and the data collection, analyzed and interpreted the data, drafted the manuscript, agreed to the final version of the manuscript, and agreed to be accountable to all aspects of this work.

\section{ACKNOWLEDGMENTS}

We would like to thank Professor Mari Tanaka and Ms. Hoko Ohyama for their faithful assistance. The research use of the Japanese version of the Scale for the Self-Cognition is based on a contract between Professor Mari Tanaka and Dr. Susan Harter. Yosuke Kita is a qualified mental health professional (clinical developmental psychologist), and Yuki Inoue is a psychiatrist (MD) specialized in mental health of children and adolescents.

\section{FUNDING}

This work was supported in part by a Grant-in-Aid for Young Scientists (B) (26780524 to YK), Intramural Research Grant for Neurological and Psychiatric Disorders of NCNP (29-6 to YK and M. Inagaki), Health Labour Sciences Research Grant (H28Kankaku-Ippan-001 to YK and M. Inagaki), and the Meiji Yasuda Life Foundation of Health and Welfare (YK). 


\section{REFERENCES}

1. American Psychiatric Association. Diagnostic and Statistical Manual of Mental Disorders. 5th ed. Arlington, VA: American Psychiatric Association (2013).

2. National Institute for Health and Clinical Excellence. Attention Deficit Hyperactivity Disorder: Diagnosis and Management. (2008). Available from: http://www.nice.org.uk/CG72

3. Loe IM, Feldman HM. Academic and educational outcomes of children with ADHD.J Pediatr Psychol (2007) 32(6):643-54.doi:10.1016/j.ambp.2006.05.005

4. Mikami AY. The importance of friendship for youth with attention-deficit/ hyperactivity disorder. Clin Child Fam Psychol Rev (2010) 13(2):181-98. doi:10.1007/s10567-010-0067-y

5. Cunningham CE, Barkley RA. The interactions of normal and hyperactive children with their mothers in free play and structured tasks. Child Dev (1979) 50:217-24. doi:10.2307/1129059

6. Harter S. The perceived competence scale for children. Child Dev (1982) 53:87-97. doi:10.2307/1129640

7. Danckaerts M, Sonuga-Barke EJ, Banaschewski T, Buitelaar J, Dopfner M, Hollis $\mathrm{C}$, et al. The quality of life of children with attention deficit/hyperactivity disorder: a systematic review. Eur Child Adolesc Psychiatry (2010) 19:83-105. doi:10.1007/s00787-009-0046-3

8. Harpin V, Mazzone L, Raynaud JP, Kahle J, Hodgkins P. Long-term outcomes of ADHD: a systematic review of self-esteem and social function. JAtten Disord (2013) 20(4):295-305. doi:10.1177/1087054713486516

9. Jiang Y, Johnstone C. Co-occurring aggressive and depressive symptoms as related to overestimations of competence in children with attention-deficit/ hyperactivity disorder. Clin Child Fam Psychol Rev (2014) 17:157-72. doi:10.1007/s10567-013-0158-7

10. Owens JS, Goldfine ME, Evangelista NM, Hoza B, Kaiser NM. A critical review of self-perceptions and positive illusory bias in children with ADHD. Clin Child Fam Psychol Rev (2007) 10:335-51. doi:10.1007/s10567-0070027-3

11. Cook J, Knight E, Hume I, Qureshi A. The self-esteem of adults diagnosed with attention-deficit/hyperactivity disorder (ADHD): a systematic review of the literature. Atten Defic Hyperact Disord (2014) 6:249-68. doi:10.1007/ s12402-014-0133-2

12. Babinski DE, Pelham WE, Molina BG, Waschbusch DA, Gnagy EM, Yu J, et al. Women with childhood ADHD: comparisons by diagnostic group and gender. J Psychopathol Behav Assess (2011) 33(4):420-9. doi:10.1007/ s10862-011-9247-4

13. Newark PE, Elsasser M, Stieglitz R. Self-esteem, self efficacy, and resources in adults with ADHD. JAtten Disord (2012) 20(3):279-90. doi: $10.1177 / 1087054712459561$

14. Rucklidge J, Broun D, Crawford S, Kaplan B. Attributional styles and psychosocial functioning of adults with ADHD: practice issues and gender differences. J Atten Disord (2007) 10(3):288-98. doi:10.1177/1087054706289942

15. Canu WH, Carlson CL. Rejection sensitivity and social outcomes of young adult men with ADHD. JAtten Disord (2007) 10(3):261-75. doi:10.1177/1087054706288106

16. Dan $\mathrm{O}, \operatorname{Raz} \mathrm{S}$. The relationships among $\mathrm{ADHD}$, self-esteem, and test anxiety in young adults. JAtten Disord (2015) 19(3):231-9. doi:10.1177/ 1087054712454571

17. Edbom T, Lichtenstein P, Granlud M, Larsson JO. Long-term relationships between symptoms of attention deficit hyperactivity disorder and selfesteem in a prospective and longitudinal study of twins. Acta Paediatr (2006) 95:650-7. doi:10.1111/j.1651-2227.2006.tb02311.x

18. Scholtens S, Rydell AM, Yang-Wallentin F. ADHD symptoms, academic achievement, self perception of academic competence and future orientation: a longitudinal study. Scand JPsychol (2013) 54(3):205-12. doi:10.1111/ sjop. 12042

19. Glass K, Flory K, Martin A, Hankin BL. ADHD and comorbid conduct problems among adolescents: associations with self-esteem and substance use. Atten Defic Hyperact Disord (2011) 3:29-39. doi:10.1007/ s12402-010-0042-y

20. Levy F, Hay DA, McStephen M, Wood C, Waldman I. Attention-deficit hyperactivity disorder: a category or a continuum? Genetic analysis of a largescale twin study. J Am Acad Child Adolesc Psychiatry (1997) 36(6):737-44. doi:10.1097/00004583-199706000-00009
21. Asherson P, Trzaskowski M. Attention-deficit/hyperactivity disorder is the extreme and impairing tail of a continuum. J Am Acad Child Adolesc Psychiatry (2015) 54(4):249-50. doi:10.1016/j.jaac.2015.01.014

22. Harter S. Causes and consequences of low self-esteem in children and adolescents. In: Baumeister RF, editor. Self-Esteem: The Puzzle of Self-Regard. New York: Plenum (1993). p. 87-116.

23. Bongers IL, Koot HM, van der Ende J, Verhulst FC. The normative development of child and adolescent problem behavior. J Abnorm Psychol (2003) 112(2):179-92. doi:10.1037/0021-843X.112.2.179

24. Jensen PS, Shervette RE III, Xenakis SN, Richters J. Anxiety and depressive disorders in attention deficit disorder with hyperactivity: new findings. Am J Psychiatry (1993) 150:1203-9. doi:10.1176/ajp.150.8.1203

25. Treuting JJ, Hinshaw SP. Depression and self-esteem in boys with attention-deficit/hyperactivity disorder: associations with comorbid aggression and explanatory attributional mechanisms. JAbnorm Child Psychol (2001) 29:23-39. doi:10.1023/A:1005247412221

26. Inoue $Y$, Ito $K$, Kita $Y$, Inagaki M, Kaga M, Swanson JM. Psychometric properties of Japanese version of the Swanson, Nolan, and Pelham, version-IV Scale-Teacher Form: a study of school children in community samples. Brain $\operatorname{Dev}$ (2014) 36(8):700-6. doi:10.1016/j.braindev.2013.09.003

27. Richters JE, Arnold LE, Jensen PS, Abikoff H, Conners CK, Greenhill LL, et al. NIMH collaborative multisite multimodal treatment study of children with ADHD: I. Background and rationale. J Am Acad Child Adolesc Psychiatry (1995) 34(8):987-1000. doi:10.1097/00004583-199508000-00008

28. Swanson JM, Kraemer HC, Hinshaw SP, Arnold LE, Conners CK, Abikoff HB, et al. Clinical relevance of the primary findings of the MTA: success rates based on severity of ADHD and ODD symptoms at the end of treatment. JAm Acad Child Adolesc Psychiatry (2001) 40(2):168-79. doi:10.1097/00004583-200102000-00011

29. Gau SS, Shang CY, Liu SK, Lin CH, Swanson JM, Liu YC, et al. Psychometric properties of the Chinese version of the Swanson, Nolan, and Pelham, version IV scale - parent form. Int J Methods Psychiatr Res (2008) 17(1):35-44. doi:10.1002/mpr.237

30. Tanaka M, Wada M, Kojima M. A study of Japanese version of the scale for the self-cognition in childhood and early adolescence. Bull Grad School EducTohoku Univ (2005) 54:315-37.

31. Harter S. Manual for the Self-Perception Profile for Children. Denver, CO: The University of Denver (1985).

32. Murata T, Shimizu A, Mori Y, Oshima S. Childhood depressive state in the school situation: consideration from the Birleson's Scale. Jpn J Psychiatry (1996) 1:131-8

33. Birleson P. The validity of depressive disorder in childhood and the development of a self-rating scale: a research report. J Child Psychol Psychiatry (1981) 22(1):73-88. doi:10.1111/j.1469-7610.1981.tb00533.x

34. Ivarsson T, Gillberg C. Depressive symptoms in Swedish adolescents: normative data using the Birleson Depression Self-Rating Scale (DSRS). J Affect Disord (1997) 42(1):59-68. doi:10.1016/S0165-0327(96)00098-5

35. Hu L, Bentler PM. Cutoff criteria for fit indexes in covariance structure analysis: conventional criteria versus new alternatives. Struct Equ Modeling (1999) 6:1-55. doi:10.1080/10705519909540118

36. Byrne BM. Structural Equation Modeling with AMOS: Basic Concepts, Applications and Programming. Mahwah, NJ: Erlbaum (2001).

37. Carpenter L. The ADHD dilemma: understanding and managing the condition. In: Rogers B, editor. Teacher Leadership and Behavior Management. Thousand Oaks, CA: SAGE (2002). p. 113-27.

38. Matsuura N, Hashimoto T, Toichi M. The relationship between self-esteem and $\mathrm{AD} / \mathrm{HD}$ characteristics in the serious juvenile delinquents in Japan. Res Dev Disabil (2009) 30(5):884-90. doi:10.1016/j.ridd.2008.12.007

39. Biederman J, Munir K, Knee D, Armentano M, Autor S, Waternaux C, et al. High rate of affective disorders in probands with attention deficit disorder and in their relatives: a controlled family study. Am J Psychiatry (1987) 144:330-3. doi:10.1176/ajp.144.3.330

40. Biederman J, Newcorn J, Sprich S. Comorbidity of attention deficit hyperactivity disorder with conduct, depressive, anxiety, and other disorders. Am J Psychiatry (1991) 148:564-77. doi:10.1176/ajp.148.5.564

41. Nishikawa S, Sundbom E, Hägglöf B. Influence of perceived parental rearing on adolescent self-concept and internalizing and externalizing problems in Japan. J Child Fam Stud (2010) 19:57-66. doi:10.1007/s10826-009-9281-y 
42. Lebra TS. Mother and child in Japanese socialization: a Japan-U.S. comparison. In: Greenfield PM, Cocking RR, editors. Cross-Cultural Roots of Minority Child Development. Hillsdale, NJ: Erlbaum (1994). p. $259-74$.

43. Trommsdorff G, Essau CA. Japanese and German adolescents' control orientation: a cross-cultural study. In: Trommsdorff G, Friedlmeier W, Kornadt H-J, editors. Japan in Transition-A Comparative View on Social and Psychological Aspects. Lengerich: Pabst Science Publishers (1999). p. 198-211.

44. Leadbeater BJ, Homel J. Irritable and defiant sub-dimensions of ODD: their stability and prediction of internalizing symptoms and conduct problems from adolescence to young adulthood. JAbnorm Child Psychol (2015) 43(3):407-21. doi:10.1007/s10802-014-9908-3

45. Boylan K, Vaillancourt T, Boyle M, Szatmari P. Comorbidity of internalizing disorders in children with oppositional defiant disorder. Eur Child Adolesc Psychiatry (2007) 16(8):484-94. doi:10.7334/psicothema2013.75

46. DuPaul GJ. Parent and teacher ratings of ADHD symptoms: psychometric properties in a community-based sample. JClin Child Psychol (1991) 20:245-53. doi:10.1207/s15374424jccp2003_3

47. DuPaul GJ, Anastopoulos AD, Power TJ, Reid R, Ikeda MJ, McGoey KE. Parent ratings of attention-deficit/hyperactivity disorder symptoms: factor structure and normative data. J Psychopathol Behav Assess (1998) 20:83-102. doi:10.1037/pas0000166

48. DuPaul GJ, Schaughency EA, Weyandt LL, Tripp G, Kiesner J, Ota K, et al. Self-report of ADHD symptoms in university students: cross-gender and cross-national prevalence. JLearn Disabil (2001) 34(4):370-9. doi:10.1177/002221940103400412

49. Davis JM, Takahashi T, Shinoda H, Gregg N. Cross-cultural comparison of ADHD symptoms among Japanese and US university students. Int J Psychol (2012) 47(3):203-10. doi:10.1080/00207594.2011.614617

50. Repetti RL, Taylor SE, Seeman TE. Risky families: family social environments and the mental and physical health of offspring. Psychol Bull (2002) 128(2):330-66. doi:10.1037//0033-2909.128.2.330

51. Kuhne M, Schachar R, Tannock R. Impact of comorbid oppositional or conduct problems on attention-deficit hyperactivity disorder. J Am Acad Child Adolesc Psychiatry (1997) 36(12):1715-25. doi:10.1097/00004583-199712000-00020

52. Connor DF, Doerfler LA. ADHD with comorbid oppositional defiant disorder or conduct disorder: discrete or nondistinct disruptive behavior disorders? J Atten Disord (2008) 12(2):126-34. doi:10.1177/1087054707308486

Conflict of Interest Statement: The authors declare that the research was conducted in the absence of any commercial or financial relationships that could be construed as a potential conflict of interest.

Copyright $(2) 2017$ Kita and Inoue. This is an open-access article distributed under the terms of the Creative Commons Attribution License (CC BY). The use, distribution or reproduction in other forums is permitted, provided the original author(s) or licensor are credited and that the original publication in this journal is cited, in accordance with accepted academic practice. No use, distribution or reproduction is permitted which does not comply with these terms. 